\title{
Effect of Crossfit Training on Jump and Strength
}

\author{
Oğuzhan Yüksel ${ }^{1}$, Bolat Gündüz ${ }^{1}$, Mert Kayhan ${ }^{1}$ \\ ${ }^{1}$ School of Physical Education and Sports, Kutahya Dumlupinar University, Kutahya, Turkey \\ Correspondence: Oğuzhan Yüksel, Germiyan Campus, School of Physical Education and Sports, 43150, Kutahya, \\ Turkey.
}

Received: November 19, 2018

Accepted: December 19, 2018 Online Published: December 21, 2018

doi:10.11114/jets.v7i1.3896

URL: https://doi.org/10.11114/jets.v7i1.3896

\begin{abstract}
The purpose of this study is to investigate the effect of regular CrossFit training on some force and jump parameters. 32 healthy wrestling men participated in the study, 16 experimental and 16 control groups. For the experimental group, CrossFit training, known as Cindy, was practiced three times a week for 8 weeks. The training consisted of 5 bars, 10 push-ups and 15 squats for 20 minutes. The control group continued the classical wrestling practice. Myotest accelerometric system was used for measurements of participants' values. For the analysis of the data, repeated measure ANOVA was used. According to the results, as a result of CrossFit training, athletes' squat jump heights increased (Wilks' Lambda $=.541, \mathrm{~F}(1,30)=25, \mathrm{p}=.00)$. The mean post-training leap values $(33.778 \pm 5.48)$ were higher than the pre-training leap values $(32.169 \pm 4.95)(\mathrm{p}<0.05)$. It can be concluded that Cindy CrossFit studies improve jumping and strength ability.
\end{abstract}

Keywords: squat jump, wrestling, cindy crossfit

\section{Introduction}

CrossFit ${ }^{\circledR}$ (CrossFit, Inc., Washington, DC, USA), which is very popular in recent years, is a high intensity interval training model that includes many functional movements (Butcher et al., 2015). CrossFit training is the overall strength and conditioning program. This program was initially developed for military training and is increasingly popular among civilian population. CrossFit workouts are usually high intensity strength exercises. This training method include fast, repetitive movements with short or no rest periods. Individuals who participate in regular CrossFit training are seen to develop muscle endurance and strength over time (Yüksel et. al., 2017). CrossFit is a fast-growing fitness sport, not just a form of competition, but also a form of general exercise training. Within the currently available literature, CrossFit has recently identified significant advances in health and wellness (Kliszczewicz et al., 2014). In addition, CrossFit training is affected both by cardiovascular and anaerobic performance (Smith et al., 2013). As with other strength training models, The CrossFit training model also improves the power performance derived via anaerobic metabolism. However, while other strength training has a structure that includes rest and work cycle, CrossFit has a structure that goes on continuously. Most CrossFit training protocols do not have a rest period so that individuals have the ability to produce high power. Beside these, the individuals try to make movements as fast as possible or to complete as much work as possible within a given time period (Escobar et al., 2017). High intensity interval training and body weight training are among the top three on the worldwide fitness trend list of 2017 (Thompson, 2017). The "Cindy CrossFit" training model that used in our study also includes this two training types.

A CrossFit model such as Cindy CrossFit should include resistance and durability models to develop physical fitness parameters such as strength, power, and durability within an exercise program. The CrossFit programming philosophy is called workouts of the day (WODs) (Glassman, 2005). The aim of the WODs is to complete the exercises as fast as possible and high intensity session (Kliszczewicz et al., 2014). Maté-Muñoz et al. in their study on healthy man found that heart rate mean values 193, rate of perceived exertion values 17.62 and lactate level $12.02 \mathrm{mmol} \cdot \mathrm{L}^{-1}$ after Cindy CrossFit training. According to these responses, Cindy WODs were described as high intensity (Maté-Muñoz et al., 2018). Additionally, heart rate values equivalent to vigorous exercise according to the American College of Sports Medicine (Garber el. al., 2011).

With this study, it is aimed to review the effects of 8-week Cindy CrossFit exercises, which are scheduled three times a week, on changes over certain physical and motoric attributes and vertical jumping performance of male athletes of the adult age group, which is $19-24$. 


\section{Method}

32 male wrestlers (16 experimental and 16 control) playing in regional basketball league have participated in the study (age; $21.72 \pm 1.40$ years). Participants were randomly divided two groups and both groups were measured at same time on pre- and posttests. For the experimental group, CrossFit training, known as Cindy, was practiced three times a week for 8 weeks. The CrossFit named workout "Cindy" consists of as many rounds possible of 5 pull-ups, 10 push-ups, and 15 air squats in 20-minutes. Participants began a 5-minute warm up on the exercise bike at a self-selected intensity followed by a 1-minute rest. The workout required that the individual complete all prescribed repetitions for the movement before moving on to the next exercise and to do so as fast as possible. For example, all 10 push-ups must be completed before moving on to the 15 air squats. Each move is standardized to ensure consistency across all wrestlers. The control group continued the classical wrestling practice. Myotest accelerometric system (Myotest SA, Sion, Switzerland) was used to measure the squat jump and bench press force values of the participants. The participants jumped 5 times with beeps from the device so that their hands were on the hips and knee positions were $90^{\circ}$. Participants were instructed to jump as high as possible without performing any countermovement before the carry out of the jump. For Bench Press Force Measurement; five repetitive tests were performed with weights corresponding to $30 \%$ of the 1 repeat maximum. Data process and analysis collected data were processed with SPSS 23 program. For the analyses of the data; descriptive statistics and two-way repeated measures of ANOVA was used.

\section{Findings}

Table 1. Descriptive Data of Participants

\begin{tabular}{cccc}
\hline Variables & N & Mean & Standard Deviation (Sd) \\
\hline Age (year) & 32 & 21.72 & 1.40 \\
Weight $(\mathbf{k g})$ & 32 & 72.54 & 10.28 \\
Height $(\mathbf{c m})$ & 32 & 175.22 & 5.75
\end{tabular}

The mean age of the 32 athletes in our study was $21.72 \pm 1.40$ years, the mean body weight was $72.54 \pm 10.28$ kilograms, and the average height was determined as $175.22 \pm 5.75$ centimeters.

Table 2. Comparison of Squat Jump Values

\begin{tabular}{|c|c|c|c|c|c|c|}
\hline Variables & & $\mathbf{N}$ & $\begin{array}{l}\text { Pre-test } \\
(\text { Mean } \pm \text { Sd })\end{array}$ & $\begin{array}{l}\text { Post-test } \\
(\text { Mean } \pm \text { Sd) }\end{array}$ & $\begin{array}{l}\text { Group } \times \text { Time } \\
\text { (F) }\end{array}$ & $\mathbf{p}$ \\
\hline \multirow{2}{*}{$\begin{array}{l}\text { Vertical } \\
\text { (cm) }\end{array}$} & $\begin{array}{l}\text { Experimental } \\
\text { Group }\end{array}$ & 16 & $32.75 \pm 6.19$ & $35.97 \pm 6.33$ & \multirow[t]{2}{*}{$25.449 *$} & \multirow[t]{2}{*}{.00} \\
\hline & Control Group & 16 & $31.58 \pm 3.40$ & $31.70 \pm 3.36$ & & \\
\hline \multirow{2}{*}{$\begin{array}{l}\text { Vertical Jump } \\
\text { Speed }(\mathrm{cm} / \mathrm{sec})\end{array}$} & $\begin{array}{l}\text { Experimental } \\
\text { Group }\end{array}$ & 16 & $250.88 \pm 24.39$ & $254.63 \pm 30.87$ & \multirow{2}{*}{.525} & \multirow{2}{*}{.474} \\
\hline & Control Group & 16 & $254.06 \pm 22.74$ & $253.52 \pm 23.12$ & & \\
\hline
\end{tabular}

According to the results, the squat jump height of the athletes increased as a result of CrossFit training (Wilks' Lambda $=.541, \mathrm{~F}(1,30)=25, \mathrm{p}=.00)$.

Table 3. Comparison of Bench Press Values

\begin{tabular}{|c|c|c|c|c|c|c|c|}
\hline Variables & & & $\mathbf{N}$ & Pre-test $($ Mean $\pm S d)$ & $\begin{array}{l}\text { Post-test } \\
(\text { Mean } \pm \text { Sd })\end{array}$ & $\begin{array}{l}\text { Group } \times \text { Time } \\
\text { (F) }\end{array}$ & $\mathbf{p}$ \\
\hline \multirow{2}{*}{$\begin{array}{l}\text { Bench } \\
\text { Strength }(\mathbf{n} / \mathbf{k g})\end{array}$} & \multirow{2}{*}{ Press } & $\begin{array}{l}\text { Experimental } \\
\text { Group }\end{array}$ & 16 & $436.94 \pm 35.315$ & $452.25 \pm 35.55$ & \multirow[t]{2}{*}{$7.334 *$} & \multirow[t]{2}{*}{.011} \\
\hline & & Control Group & 16 & $431.13 \pm 39.24$ & $432.63 \pm 39.83$ & & \\
\hline \multirow{2}{*}{$\begin{array}{l}\text { Bench Press } \\
\text { Speed }(\mathrm{cm} / \mathrm{sec})\end{array}$} & \multirow[t]{2}{*}{ Bar } & $\begin{array}{l}\text { Experimental } \\
\text { Group }\end{array}$ & 16 & $129.06 \pm 16.66$ & $147.00 \pm 22.05$ & \multirow[t]{2}{*}{$13.691^{*}$} & \multirow[t]{2}{*}{.001} \\
\hline & & Control Group & 16 & $130.54 \pm 22.73$ & $134.20 \pm 23.62$ & & \\
\hline
\end{tabular}

According to the results, the bench press force values of the athletes increased as a result of CrossFit training (Wilks' Lambda $=.804, \mathrm{~F}(1,30)=25, \mathrm{p}=.011)$. There was also a significant increase in bar lift rates at the bench press position $($ Wilks' Lambda $=.687, \mathrm{~F}(1,30)=25, \mathrm{p}=.001)$. 


\section{Discussion and Result}

The purpose of this study was to examine effects of CrossFit training on bench press strength and jump parameters for wrestlers. Results indicated that 8 weeks CrossFit training had effectiveness on jump performance and strength.

Similar results were found in studies focusing on standing jump performance. Eather et. al. found improving standing jump performance on 96 adolescents. In their study, physical fitness parameters can be improved in a safe, effective and interesting way via to the CrossFit Teens program in secondary education physical education courses in adolescents (Eather et al., 2015). Besides, Greg Glassman, in his study in 2006, found that the CrossFit program was more effective in gaining strength than Canadian Army Fitness program (Glassman, 2006). Sparkes and Behm reported in 2010 that they compared a CrossFit-like unstable training method with the stable training method in their study and improved the counter movement jump performance with the CrossFit-like unstable training method. 10 men and 8 women resistance trained three days in a week under unstable training conditions for eight weeks (Sparkes and Behm, 2010). Sousa et. al. report that CrossFit training participants showed a greater countermovement jump height compared to the resistant training participants (Souza et. al., 2016). CrossFit Cindy training program is a structure that stimulates anaerobic metabolism. Due to its continuous structure, it exceeds the anaerobic threshold and stimulates the body's anaerobic metabolism. Thus, it is expected that the jump and bench press force performances dominated by anaerobic metabolism will be improved after eight weeks. Fernandez-Fernandez et. al. in a study on the acute physiological effects of Cindy CrossFit training heart rate averages were found to be $182.2 \pm 6.6$ beat/minute and blood lactate averages were found to be $14.5 \pm 3.2 \mathrm{mmol} \cdot \mathrm{l}^{-1}$. This result shows that anaerobic metabolism is predominant because of maximal heart rate of $81 \%$ and over the training period of the participants. (Fernandez-Fernandez et al., 2015). Otherwise, Kliszczewicz et. al. in a study on the metabolic and cardiovascular response to the CrossFit workout Cindy heart rate averages were found to be $186 \pm 11 \mathrm{beat} /$ minute (Kliszczewicz et. al., 2014).

CrossFit training is a method that bases on overall body endurance and strength, rather than developing a certain motor skill of the body. Perna et. al. reported in 2017 that they compared high intensity CrossFit training and high intensity swimming training and increased muscle strength with CrossFit training (Perna et. al., 2017). Heinrich et al. in 2015, participants between the ages of 35 and 65 were applied CrossFit like high-intensity functional training in 3 times a week for 5 weeks. As a result, there was a significant difference in lower extremity power and strength (Heinrich et al., 2015). Gerhart in the study on the compared traditional resistance training with Crossfit training maximal strength values were found higher in the CrossFit training group (Gerhart, 2013). Dilber and Doğru investigated effects of high-intensity functional exercises on anthropometric and physiological characteristics in 2018. It was determined that there was an increase in the leg strength and left and right hand grip strength (Dilber and Doğru, 2018). In our study, there is statistically significant increase in the strength of the participants.

As a result, CrossFit Cindy training was significantly higher compared to the classic wrestling training in terms of squat position vertical jump height, bench press force and bench press bar speed. Therefore, coaches will be able to develop training programs by organizing CrossFit training programs together with classic wrestling training therefore it will be more effective to improve sportive performance.

\section{References}

Butcher, S. J., Neyedly, T. J., Horvey, K. J., \& Benko, C. R. (2015). Do physiological measures predict selected CrossFit ${ }^{\circledR}$ benchmark performance? Open Access Journal of Sports Medicine, 6, 241-247. https://doi.org/10.2147/OAJSM.S88265

Dilber, A. O., \& Doğru, Y. (2018). The Effect of High-Intensity Functional Exercises on Anthropometric and Physiological Characteristics in Sedantery. International Journal of Sports Exercise \& Training Sciences, 4(2), 6469. https://doi.org/10.18826/useeabd.425483

Eather, N., Morgan, P., \& Lubans, D. (2015). Improving health-related fitness in adolescents: The CrossFit Teens randomized controlled trial. Journal of Science and Medicine in Sport, 19S, e2-e32. https://doi.org/10.1016/j.jsams.2015.12.406

Escobar, K. A., Morales, J., \& Vandusseldorp, T. A. (2017). Metabolic Profile of a CrossFit Training Bout. Journal of Human Sport and Exercise, 12(4), 1248-1255. https://doi.org/10.14198/jhse.2017.124.11

Fernandez-Fernandez, J., Sabido-Solana, R., Moya, D., Sarabia, J. M., \& Moya, M. (2015). Acute Physiological Responses During CrossFit ${ }^{\circ}$ Workouts. European Journal of Human Movement, 2015:35, 1-25.

Garber, C. E., Blissmer, B., Deschenes, M. R., Franklin, B. A., Lamonte, M. J., Lee, I. M, .. Swain, D. P. (2011) Quantity and quality of exercise for developing and maintaining cardiorespiratory, musculoskeletal, and neuromotor fitness in apparently healthy adults: Guidance for prescribing exercice. American College of Sports Medicine Position Stand. Medicine and Science in Sports an Exercise 43, 1334-1359. 
https://doi.org/10.1249/MSS.0b013e318213fefb

Gerhart, H. D. (2013). A Comparison of CrossFit Training to Traditional Anaerobic Resistance Training in Terms of Selected Fitness Domains Representative of Overall Athletic Performance. Theses and Dissertations (All), 1175.

Glassman, G. (2005). www.crossfit.com. The CrossFit Journal Articles, 40, 1-5.

Glassman G. (2006). Validity of CrossFit Tested. The CrossFit Journal Articles, 41, 1-4.

Heinrich, K. M., Becker, C., Carlisle, T., Gilmore, K., Hauser, J., Frye, J., \& Harms, C. A. (2015). High-Intensity Functional Training Improves Functional Movement and Body Composition Among Cancer Survivors: A Pilot Study. European Journal of Cancer Care, 24, 812-817. https://doi.org/10.1111/ecc.12338

Kliszczewicz, B., Snarr, R. L., \& Esco, M. (2014). Metabolic and Cardiovascular Response to the CrossFit Workout 'Cindy': A Pilot Study. J Sport Human Perf, 2(2), 1-9.

Maté-Muñoz, J. L., Lougedo, J. H., Barba, M., Cañuelo-Márquez, A. M., Guodemar-Pérez, J., García-Fernández, P., .... Garnacho-Castaño, M. V. (2018). Cardiometabolic and Muscular Fatigue Responses to Different CrossFit ${ }^{\circledR}$ Workouts. Journal of Sports Science and Medicine, 17, 668-679.

Perna, S., Bologna, C., Agosti, I. D., \& Rondanelli, M. (2017). High Intensity CrossFit Training Compared to High Intensity Swimming: A Pre-Post Trial to Assess the Impact on Body Composition, Muscle Strength and Resting Energy Expenditure. Asian J Sports Med, 9(1), e13843. https://doi.org/10.5812/asjsm.13843

Smith, M. M., Sommer, A. J., Starkoff, B. E., \& Devor, S. T. (2013). CrossFit-Based High-Intensity Power Training Improves Maximal Aerobic Fitness and Body Composition. Journal of Strength and Conditioning Research, 27(11), 3159-3172. https://doi.org/10.1519/JSC.0b013e318289e59f

Sousa, A. F. M. D., Santos, G. B. D., Reis, T. D., Valerino, A. J. R., Rosso, S. D., \& Boullosa, D. A. (2016). Differences in Physical Fitness between Recreational CrossFit ${ }^{\circledR}$ and Resistance Trained Individuals. Journal of Exercise Physiology Online, 19(5), 112-122.

Sparkes, R., \& Behm, D. G. (2010). Training Adaptations Associated with an 8-Week Instability Resistance Training Program with Recreationally Active Individuals. Journal of Strength and Conditioning Research, 24(7), 19311941. https://doi.org/10.1519/JSC.0b013e3181df7fe4

Thompson, W. R. (2016). Worldwide Survey of Fitness Trends For 2017. ACSM's Health \& Fitness Journal, 20(6), 8 17.

Yüksel, O., Erzeybek, M. S., Kaya, F., \& Gülaç, M. (2017). Farklı Kuvvet Antrenmanlarının Kadın Sporcularda Beden Kompozisyonuna Etkileri. Turkiye Klinikleri J Sports Sci, 9(3), 101-107. https://doi.org/10.5336/sportsci.2017-54921

\section{Copyrights}

Copyright for this article is retained by the author(s), with first publication rights granted to the journal.

This is an open-access article distributed under the terms and conditions of the Creative Commons Attribution license which permits unrestricted use, distribution, and reproduction in any medium, provided the original work is properly cited. 